\title{
The Power of Civility: A Transdisciplinary Examination of Adolescent Social Power and Bullying
}

\author{
Anthony A. Volk, Richard C. Mitchell, and Tauhid Khan
}

\begin{abstract}
Anthony A. Volk is a professor in child and youth studies at Brock University. He studies parenting, bullying, personality, and the evolution of childhood. He uses multi- and transdisciplinary methods to gain a better understanding of why children, adolescents, and parents behave the way they do. His work has been published in health, psychology, education, sociology, anthropology, social work, and education journals. Email: tvolk@brocku.ca
\end{abstract}

Richard Mitchell is a transdisciplinary scholar whose work focuses on child rights. A former social worker, Mitchell is an active scholar whose work promotes the rights of children across the globe, particularly from the perspective of the UN Convention on the Rights of the Child. A passionate believer in transdisciplinary thinking, Dr. Mitchell offers multiple undergraduate and graduate courses that highlight the value and challenges associated with transdisciplinary thinking. He has also been active in promoting environmental sustainability and Indigenous rights within the Niagara region. Email: rmitchell@brocku.ca

Tauhid Khan did his MSS in sociology at the University of Dhaka, Bangladesh, and MA in child and youth studies at Brock University. He taught sociology in different public and private universities for six years in Bangladesh. He is currently pursuing a PhD in public health and health systems at the University of Waterloo. He has research experiences (qualitative, quantitative, and mixed method) through a number of theoretical lenses in different fields of social sciences, especially sociology, including sexuality, intimacy, sex education, crime, and health. Email: thkhan85@gmail.com

Adolescents are keenly aware of the importance of social power, leading some to bully others in order to acquire and/or maintain that social power. Traditional efforts to understand and prevent adolescent bullying have largely proven to be limited or ineffective. In response to this, researchers have called for a transdisciplinary approach to bullying. Unfortunately, a transdisciplinary approach is challenging to implement, partly because it depends on, and is sometimes constrained by, the successful implementation of civility. We suggest that civility may not only be required for research but may also serve as a key for transdisciplinary efforts to understand and guide adolescents' use of social power.

Key words: adolescence; power; social power; bullying; transdisciplinary

to obtain desired goals. Research on adolescent bullying has made it unfortunately clear that one such goal is the selfish pursuit of social power (i.e., dominance, popularity, and a powerful reputation; Goodboy, Martin, \& Rittenour, 2016; Juvonen \& Graham, 2014; Olthof, Goossens, Vermande, Aleva, \& van der Meulen, 2011; Pellegrini \& Long, 2002; Sijtsema, Veenstra, Lindenberg, \& Salmivalli, 2009). Across cultures, adolescents who
Adolescence is a tumultuous time in development when, among other changes, social power becomes increasingly salient (Cillessen \& Rose, 2005). One expression of this increased focus on power is an increased level of social competition that manifests as bullying behaviour (Reijntjes et al., 2013). Bullying occurs when, within the context of a power imbalance, one individual pursues their goals by harming another (Volk, Dane, \& Marini, 2014). This is a deliberately broad definition that can apply to adult business practices or preschoolers' birthday invitations. At the same time, it can distinguish between more serious episodes of unbalanced aggression versus typically less harmful episodes of "drama" among relatively equal adolescent peers (Ybarra, Espelage, \& Mitchell, 2014). The popular stereotype of bullies as maladapted or deficient individuals does not appear to fit the evidence; most bullies (as opposed to bully-victims ${ }^{1}$ ) appear to have average or better physical and mental health, selfesteem, and other peer-desired characteristics, such as strength or attractiveness (Volk, Camilleri, Dane, \& Marini, 2012). Bullies appear to leverage these talents 
bully do indeed gain popularity and social dominance over others (Pronk et al., 2017; Reijntjes et al., 2013; Volk, Provenzano, Farrell, Dane, \& Shulman, 2019).

The success of bullying as a social tool for adolescents interested in obtaining power may explain why school strategies (Anderson \& Kincaid, 2005) and interventions have proven to be of modest, null, or even iatrogenic value for adolescents (Yeager, Fong, Lee, \& Espelage, 2015; Zych, Ortega-Ruiz, \& Del Rey, 2015). For example, school policies of zero tolerance tend to disproportionally discriminate against minorities and fail to reduce targeted behaviours (Martinez, 2009). Policies that encourage adolescents to work with peers to solve bullying problems as an intervention strategy are ironically associated with significantly higher levels of post-intervention victimization (Ttofi \& Farrington, 2011; see Smith, Salmivalli, \& Cowie, 2012 for further commentary). Thus, while there are some recent signs of hope (e.g., Gaffney, Ttofi, \& Farrington, 2018), we currently lack a proven intervention that results in large, or even medium-sized, reductions in adolescent bullying. The complex problem of designing successful interventions for adolescent bullying may account for the exponential increase of the bullying literature (Volk, Veenstra, \& Espelage, 2017). While this literature is impressive (e.g., over 5000 peerreviewed publications in the last five years), an increasing problem within the literature is a growing fracturing of theory, measures, and interpretations (Volk et al., 2017). Disciplinary boundaries, terminology, and theoretical conflict all play a role in reducing the clarity and utility of this research (Volk et al., 2017). It was for this reason that we previously called for a transdisciplinary approach to studying bullying that would literally transcend many of these issues in an effort to better tackle the problem of adolescent bullying and the abuse of power (Marini \& Volk, 2017).

\section{A transdisciplinary approach to adolescent social power and bullying}

On its surface, an academic understanding of adolescent social power seems like a relatively simple and straightforward task, yet it may represent one of the more challenging problems known to humanity. A corollary of this is the mounting evidence that the human brain, the most complex information processor currently known, evolved its impressive capacity to solve just these kinds of social problems (Dunbar, 2009). Indeed, we seem to be at least partly hard-wired to attend to this problem as even infants can differentiate between individuals who use power respectfully versus those who use power to bully others (Margoni, Baillargeon, \& Surian, 2018).

Thus, it is not surprising that unidisciplinary approaches have struggled with adequately capturing and understanding the complex phenomenon that is bullying. In response to this complexity, researchers are increasingly relying on multi- and interdisciplinary approaches to understand bullying by drawing from anthropology, biology, psychology, sociology, education, economics, computer science, media studies, visual arts, medicine, and even climate science (Copeland et al., 2014; Holben \& Zerkel, 2014; Holt, Green, TsayVogel, Davidson, \& Brown, 2017; Hong, Espelage, Hunter, \& Allen-Meares, 2018; Plimmer, Proctor-Thomson, Donnelly, \& Sim, 2017; Rinderu, Bushman, \& Van Lange, 2018; Thomas, Connor, \& Scott, 2018; Volk et al., 2012; Walton \& Niblett, 2013).

While these efforts have yielded an impressive array of new dimensions of bullying behaviour, they still do not capture the entire scope of the problem. Vaillancourt and colleagues (2008) note that there is often a significant gap between the academic discourse of bullying and what actual adolescents (i.e., the stakeholders in this issue) consider to be bullying. For example, power imbalances were the most difficult feature to accurately code, and despite representing the core distinctive component of bullying, they were mentioned by only about $30 \%$ of adolescents (Vaillancourt et al., 2008). While this was three times more frequent than for children 
(who mentioned power imbalances only about 10\% of the time; Vaillancourt et al., 2008), it does reflect that academics may not be tapping into adequate definitions of power or of bullying and/or adolescents may over- or underextend the definition of bullying. With regard to the latter, adolescents may be motivated to claim bullying when there isn't a power imbalance in order to gain sympathy or support. Conversely, they could be motivated to underreport bullying if the perpetrator is believed to be a friend or a socially desirable individual or if they wish to deny their own lack of power. These all present powerful challenges to the current validity of bullying research.

These issues may be even more critical for marginalized adolescents whose race, ethnicity, gender identity, health, and/or exceptionalities are often overlooked by most general research (e.g., see the special issue journal introduced by Hong, Peguero, \& Espelage, 2018). In many cases this marginalization not only increases the complexity of the problem, but it is also accompanied by higher levels of bullying that may include systemic forms of bullying that differ from more traditionally captured forms of bullying (Haines-Saah, Hilario, Jenkins, $\mathrm{Ng}$, \& Johnson, 2018). Nor is it always easy to translate research across different global cultures (Smith, Kwak, \& Toda, 2016), particularly when one considers public versus academic perceptions of bullying (Puhl et al., 2016). One potential solution to these problems is to use theoretical perspectives that are deliberately not limited by disciplinary silos or to studying normalized subject populations. To our knowledge, there is one such approach that may prove useful in understanding adolescent power and bullying: transdisciplinary theory (Marini \& Volk, 2017). Transdisciplinarity can be defined as research that operates simultaneously between disciplines, across different disciplines, and beyond all academic disciplines (Nicolescu, 2002).

The concept of transdisciplinarity remains controversial in some circles (Martin, 2017; Mitchell \& Moore 2015a, 2015b). This controversy exists despite having the academic discourse on this reform movement in research and teaching begin within postsecondary education systems around the world in the early 1970s (Bernstein, 2015; Choi \& Pak, 2006, p. 359; Groen et al., 2010; Leavy, 2011; Martin, 2017; Montuori, 2010, 2013; Morin, 1999; Nicolescu, 2002, 2008). As Desmond Manderson (2000) emphasizes, "the aim of bringing together diverse disciplines in a transdisciplinary project is not to transcend that knowledge base but rather to transform it" ( $\mathrm{p}$. 91). Canadian health scientists Choi and $\operatorname{Pak}(2006,2007,2008)$, in their meta-analysis of international literature of that day citing this concept, reviewed hundreds of papers published between 1982 and 2006 and found the notion being deployed interchangeably with multi- and interdisciplinarity, and most often without clear comprehension of its distinctive dimensions.

In many ways, this resembles the confusion and profusion of the use of the word bullying by academics and the general public (Volk et al., 2017; Vaillancourt et al., 2008). Martin (2017, p. 40) notes that in "transdisciplinary research" the whole is not only greater than the sum of its parts, but also has "qualitatively different characteristics." As Choi and Pak (2006, p. 359, citing Dixon, Smilek, Cudahy, \& Merikle, 2000, p. 365) have astutely framed these characteristics from their meta-analysis: within multidisciplinary teams, two plus two equals four. Within interdisciplinary teams, two plus two equals five due to the sum of the whole being greater than the sum of its parts. Within transdisciplinary teams sharing distinct paradigmatic, methodological, and analytical strategies, two plus two often equals yellow! In other words, transdisciplinary thinking can lead to outcomes that transcend what is understood and/or expected within traditional disciplinary boundaries. Given the inherent complexities associated with bullying, this appears to be a particularly useful approach for capturing the complexity of the problem. Montuori (2008), in his foreword to Nicolescu's Transdisciplinarity: Theory and Practice, notes there are four key dimensions to this "new way of thinking" (p. xi).

First, there is a focus that is inquiry driven rather than discipline specific. This does not involve a rejection 
of disciplinary knowledge, but the development of pertinent knowledge for the purposes of action in the world. In this way, transdisciplinary knowledge adopts a pragmatic, yet humble, epistemological approach. Second, there is a stress on the construction of knowledge through an appreciation of the meta-paradigmatic dimension - in other words, the underlying assumptions that form a paradigm through which disciplines and perspectives construct new knowledge. Disciplinary knowledge typically does not question its own paradigmatic assumptions, but a transdisciplinary approach explicitly encourages challenging dominant disciplinary preconceptions. Third, it entails an understanding of the organization of knowledge, isomorphic at the cognitive and institutional levels, the history of reduction and disjunction (what Morin [1999] refers to as simple thought) and the importance of contextualization and connection (or complex thought). In this way transdisciplinary thinking explicitly acknowledges the power structures and rules that underlie knowledge generation and mobilization. Finally, there is the integration of the knower in the process of inquiry, which means that rather than attempting to eliminate the knower, the effort becomes one of acknowledging and making transparent the knower's assumptions and the process through which they construct knowledge. This thereby removes disciplinary defenses from the knower and encourages them to conform to broader norms of civil discourse.

To these four dimensions found through a diverse transdisciplinary literature over decades, many recent transdisciplinary authors are also including Indigenous knowledge systems (or IKS), for example, Christie (2006), DuPlessis, Sehume, and Martin (2014), Leavy (2011), and Mitchell and Moore (2018). These efforts are particularly acute given the vulnerability of Indigenous adolescents to bullying (Gloppen, McMorris, Gower, \& Eisenberg, 2018; Melander, Hartshorn, \& Whitbeck, 2013). What's more, transdisciplinary research transcends the usual gap between academia and the broader public by acknowledging the value of knowledge obtained from diverse, nonacademic stakeholders in various communities, government, and business (Somerville \& Rapport, 2000). Indeed, two decades ago Morin and Kern (1999), looking forward to our own day, observed that transdisciplinary thinking would be an essential pathway for uniting disparate methods of thinking to approach problems that seemed intractable to any single disciplinary approach (e.g., bullying). In child and youth studies, this includes the direct participation and input at various levels within research projects by interested and committed populations of young people themselves, hence this contribution to the burgeoning global discourse. This can be challenging, particularly when power differences prevent adolescents from speaking freely, and may be challenging for youth who are marginalized or lack power within their peer group (Marini \& Volk, 2017). An increasing number of national initiatives are being set up to address the transnational and transdisciplinary nature of bullying by linking researchers to government, NGO, and public arenas of power and discourse (Pepler et al., 2006; Pepler, Cummings, \& Craig, 2016; Spiel, Salmivalli, \& Smith, 2011). Indeed, it was these transdisciplinary efforts (specifically, the voice of a father whose child was killed in a one-time episode of bullying, see Make Children Better Now Association, 2019) that motivated the removal of frequency as a criterion for bullying (Volk et al., 2014).

These transdisciplinary efforts appear to be supported by numerous authors (Mitchell \& Moore, 2015b, pp. 407-408; also Gillis, Nelson, Driscoll, Hodgins, Fraser \& Jacobs, 2017; Kueffer, Underwood, Hirsch Hadorn, Holderegger, Lehning, Pohl, \& Schirmer, 2012) who have made concrete recommendations regarding how to foster transdisciplinary university-community research collaborations by identifying numerous common facets shared by different groups. Thus, for example, new bullying research approaches could focus on the inclusion of currently excluded and diverse epistemological insiders who traditionally lack power in an academic setting (Hong, Peguero, \& Espelage, 2018). These include groups-minoritized communities; children and young people; women's groups; poverty activists; LGBTQ individuals; Indigenous communities, individuals, and Elders; migrant labourer and refugee populations; along with nonacademic and nongovernmental organizations, civil society, and small business - all acting as full partners in problem-centered research projects. When asked by a 
colleague what transdisciplinary thinking offers beyond an appreciation of complexity (which interdisciplinary research acknowledges and deals with), our fundamental reply was epistemological humility-the simple notion that singular disciplinary knowledge is incomplete (see also Montuori, 2008). A transdisciplinary approach recognizes that complex problems like bullying often have nonlinear solutions that require moving beyond disciplinary approaches to incorporate input from a host of nonacademic sources (Pepler et al., 2006, 2016).

Epistemological humility tells us that complexity can lead to the problem of unanticipated outcomes (Montuori, 2010), or "black swans." The concept of the black swan was popularized by Nassim Taleb in the context of his economic research and encapsulates the idea that until the discovery of Australian black swans by John Latham in 1790, all swans were believed to be white. The discovery of an atypical species of swan required a major revision to the definition and even the concept of a swan. When this notion is applied to adolescent bullying it means our understanding of that behaviour is vulnerable to unknown events. One such example is the advent of cyberbullying, which might have surprised academic researchers but would likely have not had researchers adopted a transdisciplinary approach that directly involved adolescent stakeholders who were more conversant in, and aware of, the potentials of new technology. In other words, a transdisciplinary approach adopts an intellectual humility that encourages transdisciplinary breadth as an insurance against overlooking important phenomena. Failing to attend to information from a diversity of sources can lead to artificially narrow disciplinary hypotheses that fail (sometimes spectacularly) in the face of real-world data.

Thanks to highly visible media cases (e.g., CBC News, 2013), researchers are now aware of the importance of incorporating cyberbullying into research (Volk et al., 2017). The existence and impact of previously unknown events (e.g., the novel use of technology to bully others) may be particularly likely when discussing adolescent power and bullying given the secretive nature of many adolescents (Bakken \& Brown, 2010). Although adolescents can, at times, be quite candid (Spadafora, Marini, \& Volk, 2018), they can also potentially withhold important information from adults. That is why it is crucial for researchers to seek out information from insider stakeholders themselves (i.e., adolescents) in order to get their perspectives (Bosacki, Marini, \& Dane, 2006). This may be particularly important for marginalized groups who inherently distrust the authority of researchers (e.g., cyberbullying amongst Indigenous adolescents; Broll, Dunlop, \& Crooks, 2018). There have already been calls to differentiate between etic (e.g., outsiders like researchers) and emic (e.g., insiders like adolescents) perspectives on bullying (Holt et al., 2017). Fortunately, transdisciplinary research, by its very nature, offers a breadth of study that renders such research less susceptible to the presence and influence of unknowns or black swans (Pohl \& Hirsch Hadorn, 2007). By incorporating a diverse swath of opinions (e.g., Holt et al., 2017; Hong, Espelage, Hunter, \& Allen-Meares, 2018; Melander et al., 2013), bullying researchers can construct transdisciplinary theories that are more robust than those constructed without such previously unknown information (Marini \& Volk, 2017). What's more, they are more likely to provoke the discovery of such sources of information by actively exploring outside of known disciplinary domains. In this way a weakness of disciplinary approaches (e.g., an ugly fact spoiling a beautiful theory) becomes a relative strength of a transdisciplinary approach that emphasizes the importance of epistemological humility as a means of leading to data and theoretical constructions that lie beyond the scope of traditional boundaries.

However, this diversity comes at a price. There clearly exists a degree of challenge in conducting transdisciplinary research. Transdisciplinary research requires that one become familiar with a range of research and discourse within, and outside of, academia (Pohl \& Hirsch Hadorn, 2008). This by itself requires significant mental effort. However, knowledge is a precious commodity that is often fought over (Constant, Kiesler, \& Sproull, 1994). Disciplinary biases and predispositions can be very challenging to overcome, both at the individual level and at the level of publication/knowledge mobilization (Cohen, 2009). The challenge of dealing with different 
viewpoints and disciplines means that a transdisciplinary approach should be characterized, not just by humility, but also by civility.

\section{Is civility both the medium and the message?}

Civility can be defined as "the ability to act as a 'citizen' of a group and function in a positive manner so that individual engagement can benefit both the individual and the group" (Marini, 2007, p. 1). In this way, civility can be represented as a multifaceted construct that be construed of as a behaviour, as a cultural set of norms, or as an individual trait. Civility can thus possess both objective and subjective domains (Hefner, 2018) and is a concept and behaviour that cuts across and beyond disciplines (Carter, 1998). Much in the same way that bullying has attracted attention from diverse areas, civility has attracted attention from the general public (Papacharissi, 2004), the media (Young, 2018), policy makers (Nwanevu, 2018), historians (Shapin, 1994), psychology (Volk, Marini, \& Dane, 2016), education (Feldmann, 2001), and workplace management (Lim \& Bernstein, 2014). Thus, we believe that a transdisciplinary approach best offers a means of grappling with civility's complexity, breadth across domains and cultures, dual objectivity/subjectivity, and multifaceted nature.

Unfortunately, as has been noted (Hyun, 2011), working across and beyond academic disciplines can be a challenging and sensitive endeavour. Augsburg (2014) emphasizes the importance of openness and risk taking for becoming a transdisciplinary thinker. The former trait is common to most successful academics (Pouratashi \& Zamani, 2017), while the latter may better reflect one's career status as (anecdotally at least) it appears that most transdisciplinary scholars both have previous disciplinary experience and are beyond the vulnerable (i.e., power-imbalanced) tenure-track stage of their career (Pohl, 2005). Indeed, following social conventions and respecting others allows for the smoother transmission of ideas and information across transdisciplinary boundaries (Della Chiesa, Christoph, \& Hinton, 2009). Civility, or a lack thereof, appears to have a contagious effect on communication (Han, Brazeal, \& Pennington, 2018), rendering a transdisciplinary endeavour progressively easier or more difficult depending on its presence or absence (Hyun, 2011; Pohl, 2005). Civility has been noted as the answer to the inevitable disciplinary conflicts that arise when conducting transdisciplinary research (Benesh et al., 2015). Indeed, civility appears to promote a general sense of cooperation across domains that is based on a longer-term orientation to relationships (Billante \& Saunders, 2002; Pye, 1999), unlike bullying (Volk et al., 2014).

This may be because civility serves as an individual reminder of the importance of cooperation versus competitive relationships and offers one the chance to express one's allegiance to the common good (Billante \& Saunders, 2002). Civility is related to the personality trait of honesty-humility that promotes cooperation at the expense of taking advantage of others (Spadafora et al., submitted). Honesty-humility is associated with positive academic outcomes (de Vries, de Vries, \& Born, 2011) and also fits naturally with the concept of epistemological humility. Being honest and humble can lead, almost by necessity, to Augsburg's (2014) transdisciplinary criteria for appreciating one's limitations in comparison to others' skills and attributes, as well as to the awareness of the limitations of personal and institutional knowledge that is necessary for transdisciplinary research. As noted by Jacobs and Nienaber (2011), "it is impossible to ever perfectly solve or understand an issue completely. The pursuit of knowledge is always imperfect. Similarly there is never a perfect solution to a problem” (p. 618). Indeed, the original charter of transdisciplinarity proposed by de Freitas, Morin, and Nicolescu (1994) calls for, among other things, a deep adoption of epistemological humility via (a) a recognition of the existence of different levels of reality governed by different types of logic, (b) an attitude of absolute respect for the collective replete with shared knowledge and understandings, (c) rigour in argument, and (d) tolerance of ideas opposed to one's own. These principles are all facets of being honest and/or humble. Thus, on the one hand, honesty, 
humility, and civility can represent a medium that could facilitate future transdisciplinary bullying research.

On the other hand, to twist a common phrase, the medium may also be the message (McLuhan, 1964). In this context, more specifically, we refer to a duality of the role of civility, in that a lack of civility may hamper bullying research, but a lack of civility may also serve to embolden adolescents toward abusing their power in the form of bullying (Marini, 2009). This lack of civility appears to increase with age from early to mid-adolescence (Spadafora, Farrell, Provenzano, Marini, \& Volk, 2018), possibly because of a combination of an increased desire for reward seeking along with a diminished capacity for self-control (Steinberg, 2008). In particular, an arrogant lack of cooperativeness may allow individuals to both ignore social civility conventions and exploit social power. Many adolescents who bully in both Eastern and Western cultures do in fact appear to lack both honesty and humility (Book, Volk, \& Hosker, 2012; Volk et al., 2018). A lack of honesty may allow adolescents to not only hide their misdeeds but also to deceive themselves about the true costs of their behaviour. With regard to humility, researchers who used grounded theory to generate a bottom-up explanation of bullying found that bullies possessed a relatively arrogant belief about their own worth versus that of their victims (Mazzone, Thornberg, Stefanelli, Cadei, \& Caravita, 2018; Thornberg, 2015). This allows adolescents who bully to value their gains more than they value the harm caused to their victims. Finally, classroom incivility is positively correlated with both adolescent bullying and a lack of honesty and humility (Spadafora et al., submitted). Thus, in a very real way, a lack of civility can serve as a gateway to bullying by emphasizing short-term individual gain over long-term cooperative benefits (Marini, 2009; Pye, 1999; Volk et al., 2014). So there appears to be a strong link between bullying, (in)civility, and a personality-based tendency to arrogantly exploit others. However, as mentioned above, when viewed through a transdisciplinary lens, civility is more than a psychological trait.

A lack of adolescent civility has been documented in both modern and historical cultures, with adolescent culture being typically labelled as unruly and uncivil (e.g., Hanawalt, 1995). While these enduring historical and cross-cultural trends may tend to point toward a common, biologically based psychological predisposition for adolescent incivility, they equally raise questions about the creation and perception of civil norms. In particular, they highlight the dominance of adult voices in the discourse of civility, just as they appear to emphasize the voices of socially powerful individuals. The socially powerful (e.g., nobility, politicians), the wealthy, and the famous have a clearly established role in prescribing civil norms (Benson, 2011). Sometimes this occurs at the expense of the majority, but often it occurs at the expense of marginalized minorities (Benson, 2011). In these cases, a group with power uses social rules to reinforce their power rather than to benefit others (Callahan, 2011; Thiranagama, Kelly, \& Forment, 2018). We would consider these rules to in fact be a socially sanctioned form of bullying that is enforced by civility. It would seem that civility used outside the context of honesty and humility (e.g., a charitable prosociality) can as equally serve as a precursor of bullying, as can incivility. By logical extension, incivility can thus also act against bullying. Acting up against dominant groups (e.g., adult norms) may be a way for adolescents to resist the social power imposed on them by others. There are numerous historical examples of individuals engaging in incivil behaviour in order to resist the bullying behaviour of others (Davetian, 2009). The relationship between civility and bullying is therefore nuanced, contextual, and complexthe perfect relationship for transdisciplinary research.

\section{Civility, bullying, and transdisciplinary solutions}

An important, if problematic, concern for both civility and bullying is that there often isn't much incentive for an individual with power to forgo long-term cooperation in favour of obtaining immediate benefits. Indeed, most adolescents hold a negative view of bullying behaviour (Sentse, Veenstra, Kiuru, \& Salmivalli, 2015), yet it not only persists but continues to be a successful strategy across the world (Pronk et al., 2017). So why 
would any adolescent be concerned about potential long-term costs if those costs are largely irrelevant? Similar queries likely explain the prevalence of sexist, racist, elitist, etc. bullying or the persistence of civility norms that discriminate against other groups (e.g., civil norms that persecute women; Towns, 2010). It is in one very real (if selfish) sense highly irrational to ask people to stop benefitting from bullying or the enforcement of biased civility because it hurts others. If bullying does really get you sex, power, and resources, why should individuals stop doing it (Ellis et al., 2016; Volk et al., 2014)? What is the benefit in doing that? The stark reality of these questions is reflected in the declining efficacy of antibullying interventions during adolescence (Yeager et al., 2015): Why give up something for nothing? For those programs that have shown some degree of success, any relaxation of their efforts and bullying tends to revert to its previous levels (Roland, 2011). The temporary nature of these successes points to persistent biological and/or cultural influences that continue to promote or reward bullying and incivility. The perseverance, ubiquity, and impact of these negative behaviours raise transdisciplinary questions as they also relate to other forms of social power abuse, such as why slavery should have ever been abolished, women allowed to vote, and children given rights. Why would any individuals voluntarily relinquish their power over others for no apparent personal gain (Dawkins, 1976)? Fortunately, civility might offer us a clue as to its persistence: long-term cooperative benefits for those who design the rules of civility.

In light of the inevitability of black swans in complex systems like human social power, no particular group or individual will have a guaranteed permanent grip on power, and a reversal of power may result in a reversal of fortunes. Thus the same selfish logic that promotes bullying can also promote having the insurance of giving up some power today to make sure you aren't bullied tomorrow. It is also true that in almost every instance, cooperation results in better long-term outcomes than does competition (Wedekind \& Braithwaite, 2002; Wilkins et al., 2010). This may help explain the recent success of an anti-bullying program that focuses on working with, rather than against, adolescents' desire for social power. Adolescents appear to be keenly aware of the potential dynamics associated with social power, its acquisition, and its role in the peer group (Cillessen \& Rose, 2005; Spadafora, Farrell, et al., 2018). So interventions that try to go against these norms (e.g., relying on unpopular children to change the behaviour of popular children) tend to fail (Garandeau, Lee, \& Salmivalli, 2014). Similarly, programs that rely on intensive adult oversight and interventions offer some success but quickly lose their effects once that costly support is withdrawn (Roland, 2011). As one might expect, adolescents tend to resist adults' attempts at taking away their power, or redefining adolescent civility, as those same attempts of modelling adult civility might instead be interpreted as modelling the potential abuse of power by adults.

In contrast, programs that work with adolescents in a way that respects their own agency in discovering the benefits of prosocial civility may have better results. In one such program, called Meaningful Roles, adolescents are given jobs to perform in the class (Ellis et al., 2016). Rather than being told by adults how they can and cannot act, all students are asked to create jobs they would value and that would help the class (i.e., meaningful roles). From there, based on earlier identification, bullies are given prosocial jobs that promote civility while still affording the social visibility that they desire (e.g., being the person at the door who greets everyone who enters class/school; Ellis et al., 2016). This allows adolescents who bully the opportunity to achieve their goal of being socially visible and in a leadership role without causing harm to others, without facing any risks of punishment, and without facing peers who might otherwise respect their power, but not them individually. School-level evidence suggests that this program can reduce fighting by $66 \%$, along with significant reductions in illnesses, days off, and detentions (Ellis et al., 2016). Thus, the promotion of seemingly minor but civil roles can offer adolescents a meaningful outlet for their desires for social recognition and power. By involving adolescents in the creation of their jobs, this approach respects the rights of individuals to pursue their own goals and decisions but affords them opportunities toward civility that they might not have otherwise had. By reconfiguring the 
landscape toward prosocial civility, we can encourage adolescents to use their power to lead others rather than dominate them. This could entail the employment of transdisciplinary narratives from beyond the school setting, drawing on popular culture, art, and/or spiritual narratives (e.g., Safaria \& Yunita, 2014) to provide meaningful examples to support this reconfiguration. Rather than relying solely on adult-driven costs and benefits (i.e., punishments and rewards), we can work with adolescents and nonacademics to draw on other aspects of knowledge to emphasize the value of a longer-term outlook and allow adolescents to experience the benefits of cooperative engagements with each other.

These engagements can be both direct and indirect. For example, the historical rise of women's power and agency in Western democracies may have been a boon, not only for those women, but for children's and adolescents' welfare as well (Pinker, 2018). Women have traditionally played (and continue to play) dominant roles in the care of children and youth (Volk, 2011). So an increase in the welfare of women appears to correlate with a rise in the rights and welfare of children and youth (e.g., Hammarberg, 1990) as some women used their power to benefit the children and youth that they cared for and/or worked with. While there remains much work to be done with regard to gender inequality, the transdisciplinary message would be that gains in one domain (e.g., women's rights) can have important yet unpredicted impacts in another domain (e.g., adolescent bullying). What was formally sanctioned and viewed as a right of passage by largely white-male-dominated school boards (i.e., hazing and bullying) is now increasingly viewed as a callous, needless, and incivil abuse of power by more diverse school boards. Similarly, one could hope that the current \#MeToo movement aimed at reducing workplace sexual harassment might have indirect benefits in reducing adolescent sexual bullying by readjusting civil standards of behaviour to a more prosocial and gender egalitarian level.

\section{The power of prosocial civility}

Prosocial civility therefore may offer two clear advantages for understanding adolescent power. First, it may offer an important way of smoothing out explicit and implicit biases toward disciplinary "truths" and research goals (Billante \& Saunders, 2002; Kelly, 2017). Transdisciplinary research can present an inherent threat toward disciplinary researchers by casting their work as unimportant and/or insufficient. The former is, by any reasonable academic definition, false. We can't add $2+2$ if we don't even know what numbers we're dealing with in the first place. However, given the competitive nature of academic research, the latter might be a new reality that needs to be presented to researchers in such a way that it invites them rather than threatens them. In this way, given the complexity and scope of adolescent bullying and social power, it seems that transdisciplinary research offers the only reasonable avenue for a complete solution that involves adolescents, their parents, educators and child workers, the pubic, policy makers, marginalized groups, NGOs, and academics. Some bullying intervention efforts have already begun to use transdisciplinary research efforts (e.g., PREVNet in Canada), but in general the field has been slow to adopt transdisciplinary research as a main pillar of research and intervention efforts (Marini \& Volk, 2017).

Second, beyond using a transdisciplinary foundation of civility to study the problem at hand, the transdisciplinary nature of civility might make it part of the solution for addressing adolescents' abuse and pursuit of social power (Marini, 2009). On the one hand, this message is nothing new-adults have long preached the value of civility (Higonnet, 1992). Nor is it unique to humans. To grow up successfully, adolescent male elephants require older male elephants to teach them "prosocial civility" (Slotow, van Dyk, Poole, Page \& Klocke, 2000), and many trees grow stronger and live longer when there are adult trees present to monitor and guide their "adolescent" development according to rules of cooperation and competition (Wohlleben, 2016). Civility is a complex phenomenon that involves behaviours, traits, traditions, and contemporary sociocultural 
conditions. Understanding its applicability to bullying will require input from multiple academic, nonacademic, and nontraditional domains if we are to have a reasonable chance of being catastrophically surprised by black swans.

On the other hand, adolescents have always been at the forefront of civility by testing its boundaries and meanings (Cahill, 1987; Higonnet, 1992; Marini, 2007). Adolescents' resistance to adult interference is one of the very likely reasons why bullying interventions are so ineffective with them (Yeager et al., 2015). Yet adolescents are not impervious to adults' behaviours, and most earnestly strive to mature into successful, cooperative individuals by learning from adults around them (Arnett, 2015; Wilkins et al., 2010). An unfortunate reality is that the "adult world" itself often lacks prosocial civility and instead encourages bullying (Nwanevu, 2018) and/ or strips adolescents of their agency and power by insisting on morally neutral (or even hostile) civil deference toward adults (Cahill, 1987). Adolescents are quite likely, and accurately, able to perceive the hypocrisy in messages that promote equal sharing of power among adolescents presented by adults who do not share power with adolescents. What's more, there are real concerns about the decline of prosocial civility in modern Western society (Wilkins et al., 2010). Yet there remain bright spots of hope (Nwanevu, 2018). We can arrange our classrooms in ways that promote prosocial civility (Kauffman \& Burbach, 1998). Presumably parents, teachers, and other adults can both better model prosocial civility and arrange social structures surrounding adolescents in ways that promote civility (Wilkins et al., 2010). For it to be a transdisciplinary effort, this modelling must go beyond honest but unidisciplinary research into predefined categories and variables of behaviour (e.g., Dijkstra \& Gest, 2015). Put succinctly, adolescents may pay more attention to the prosocially civil behaviour of a single celebrity than to the results of a well-constructed meta-analysis.

What's more, we require more input from outside of academia and adult circles. Wearing a hat to the dinner table may no longer be an act of incivility in adolescent circles, while momentarily ignoring others at the table while texting on one's phone may represent a breach of civility for adults but not for adolescents. By engaging with adolescents and individuals outside of academia, and by drawing from numerous disciplines to inform our understanding, we may well be able to guide adolescents toward adopting and/or developing their own meaningful values of prosocial civility that promote a common long-term well-being (Wilkins et al., 2010). These efforts most certainly need to transcend the school, allowing adolescents to meaningfully engage with their communities and cultures to develop their own language of civility that promotes cooperation and wellbeing (Youniss \& Yates, 1999). Research on civic engagement (a component of civility) clearly demonstrates that adolescents are influenced by more than their peers and schools: parents, neighbours, and communities can all influence adolescents' uptake of civility (Rossi, Lenzi, Sharkey, Vieno, \& Santinello, 2016). These influences must now also include online interactions and communities (Young, 2018). They should also include an awareness of the legal rights, resources, and responsibilities that accompany adolescents' civic behaviour (Hammarberg, 1990; Hepworth, Rooney, Rooney, \& Strom-Gottfried, 2017; Levesque, 2000).

Thus, civility, a seemingly simple and potentially unimportant concept, might actually represent the important underpinnings of a whole range of adolescent social behaviour, including intervening against bullying (Spadafora, Farrell, et al., 2018). Fortunately, we know from research that most bullies are highly engaged in obtaining social dominance, but not all individuals who have social power become bullies (Reijentjes et al., 2013). We argue that it is the responsibility of adults across domains to model and encourage civil behaviour for adolescents (Billante \& Saunders, 2002), just as it is the duty of adolescents to study and develop their own codes of civil behaviour (Marini, 2009; Marini, Polihronis, \& Blackwell, 2010). Adults have made important strides in imbuing adolescents with an increasingly broad scope of rights and protections at the same time as adolescents have made significant strides in claiming those rights and protections for themselves (Freeman, 
2018; Hammarberg, 1990). We strongly argue that it behooves us to continue acting in this tradition with an aim toward building greater prosocial civility. As stated before, we know that if we want adolescents to responsibly use their social power (i.e., not bully others with it), the solution must ultimately come from adolescents themselves, not be imposed by adults (Yeager et al., 2015). However, by adopting a transdisciplinary perspective on adolescent social power, bullying, and civility, we may be able to learn enough to help guide adolescents in their mastery of, and engagement with, prosocial civility. Adults can also help empower the voices and knowledge of adolescents who belong to groups that are typically both marginalized and victimized by bullying (Hong, Peguero, \& Espelage, 2018). As individuals with power, adults can also demonstrate the requisite epistemological humility by inviting, and listening to, a diversity of voices in a transdisciplinary forum. For example, the PREVNet 2017 conference focused on addressing bullying by bringing in speakers from academia, business, government, NGOS, professional sports, television, child rights, restorative justice, Indigenous networks, and law. It was capped off by an evening town hall led by a diverse group of adolescents that was broadcast live over the Internet. These kinds of civil efforts to bring together diverse groups not only represent an opportunity to advance our knowledge, but in the spirit of the medium being the message they also represent a clear message to adolescents about how adults in the ivory tower can suspend their disciplinary privilege to encourage individuals from disparate groups to humbly and openly work together to respectfully share their knowledge.

Finally, adolescents can help adults understand both the failings of adult civility and what aspects of that civility may (or may not) best work for adolescents. Again, granting adolescents the respect they are due in cogenerating knowledge about bullying not only improves our knowledge of bullying, but it also offers an object lesson in how individuals with power (i.e., typically the adults) can respectfully share that power with others. The alternative to these kinds of solutions is to remain in disciplinary and age-specific silos that fail to reach beyond their borders. This is an alternative that has so far proven to be unsuccessful and will almost certainly continue to be so until we fully address the scope of the problem and any potential solutions for it. Civility may thus seem like an underwhelming goal, but as both a means and a message of transdisciplinary thinking, it may actually hold the key to adolescents' responsible use of social power and to the long-term reduction of bullying.

\section{Acknowledgements}

This paper was inspired, motivated, and informed by the work of our departed colleague Dr. Zopito Marini. Zopito inspired the metaphor of civility as both the medium and the message as he served as a living example of civility at the same time as he spread the message about its importance. We were motivated to do this paper via a strong suggestion from Zopito that we team up to address this important question. He most certainly would have joined us in this endeavour given his passion and knowledge of the topic. And it is the latter that informed much of our research. He is cited repeatedly in our references, but those fail to do justice to the extent to which he informed our work. We only hope that we have done a reasonable job of conveying what would have been his latest message about the importance of civility and transdisciplinary research for understanding adolescent social power and bullying. 


\section{References}

Anderson, C. M., \& Kincaid, D. (2005). Applying behavior analysis to school violence and discipline problems: Schoolwide positive behavior support. The Behavior Analyst, 28, 49-63. https://doi.org/10.1007/BF03392103

Arnett, J. J. (2015). Identity development from adolescence to emerging adulthood: What we know and (especially) don't know. In K. C. McLean \& M. Syed (Eds.), The Oxford handbook of identity development (pp. 53-64). New York, NY: Oxford University Press.

Augsburg, T. (2014). Becoming transdisciplinary: The emergence of the transdisciplinary individual. World Futures, 70, 233-247. https:// doi.org/10.1080/02604027.2014.934639

Bakken, J. P., \& Brown, B. B. (2010). Adolescent secretive behavior: African American and Hmong adolescents' strategies and justifications for managing parents' knowledge about peers. Journal of Research on Adolescence, 20, 359-388. https://doi.org/10.1111/j.15327795.2010.00642.x

Benesh, E. C., Lamb, L. E., Connors, S. K., Farmer, G. W., Fuh, K. C., Hunleth, J., \& Gehlert, S. J. (2015). A case study approach to train early-stage investigators in transdisciplinary research. Transdisciplinary Journal of Engineering and Science, 6, 13-22. https://doi. org/10.22545/2015/00071

Benson, T. W. (2011). The rhetoric of civility: Power, authenticity, and democracy. Journal of Contemporary Rhetoric, 1, 22-30. Retrieved from http://contemporaryrhetoric.com/wp-content/uploads/2017/01/benson1_3.pdf

Bernstein, J. (2015). Transdisciplinarity: A review of its origins, development, and current issues. Journal of Research Practice 11, Art. R! Retrieved from http://jrp.icaap.org/index.php/jrp/article/view/510/412

Billante, N., \& Saunders, P. (2002). Why civility matters. Policy: A Journal of Public Policy and Ideas, 18(3), 32-36.

Book, A. S., Volk, A. A., \& Hosker, A. (2012). Adolescent bullying and personality: An adaptive approach. Personality and Individual Differences, 52, 218-223. http://dx.doi.org/10.1016/j.paid.2011.10.028

Bosacki, S. L., Marini, Z. A., \& Dane, A. V. (2006). Voices from the classroom: Pictorial and narrative representations of children's bullying experiences. Journal of Moral Education, 35, 231-245. http://dx.doi.org/10.1080/03057240600681769

Broll, R., Dunlop, C., \& Crooks, C. V. (2018). Cyberbullying and internalizing difficulties among Indigenous adolescents in Canada: Beyond the effect of traditional bullying. Journal of Child \& Adolescent Trauma, 11, 71-79. https://doi.org/10.1007/s40653-0170163-y

Cahill, S. E. (1987). Children and civility: Ceremonial deviance and the acquisition of ritual competence. Social Psychology Quarterly, 50, 312-321. http://dx.doi.org/10.2307/2786816

Callahan, J. L. (2011). Incivility as an instrument of oppression: Exploring the role of power in constructions of civility. Advances in Developing Human Resources, 13, 10-21. https://doi.org/10.1177/1523422311410644

Carter S. L. (1998). Civility: Manners, morals, and the etiquette of democracy. New York, NY: Basic Books.

CBC News. (2013). Amanda Todd suicide: RCMP repeatedly told of blackmailer's attempts. Retrieved August 14, 2014, from http://www. cbc.ca/news/canada/amanda-todd-suicide-rcmp-repeatedly-told-of-blackmailer-s-attempts-1.2427097

Choi, B., \& Pak, A. (2006). Multidisciplinarity, interdisciplinarity, and transdisciplinarity in health research, services, education, and policy: 1. Definitions, objectives, and evidence of effectiveness. Clinical Investigation \& Medicine, 29, 351-364.

Choi, B., \& Pak, A. (2007). Multidisciplinarity, interdisciplinarity, and transdisciplinarity in health research, services, education, and policy: 2. Promotors, barriers, and strategies of enhancement. Clinical Investigation \& Medicine, 30, E224-E232. Retrieved from https://pdfs.semanticscholar.org/dffc/7102bbd6146390a1b32e2557f5385795d4e7.pdf

Choi, B., \& Pak, A. (2008). Multidisciplinarity, interdisciplinarity, and transdisciplinarity in health research, services, education, and policy: Discipline, inter-discipline distance, and selection of discipline. Clinical Investigation \& Medicine, 31, E41-E48. Retrieved from https://pdfs.semanticscholar.org/7cc4/ac195c59a8fbbff463ad10f12167d9254bce.pdf 
Christie, M. (2006). Transdisciplinary research and Aboriginal knowledge. Australian Journal of Indigenous Education, 35, 78-89. https:// doi.org/10.1017/S1326011100004191

Cillessen, A. H., \& Rose, A. J. (2005). Understanding popularity in the peer system. Current Directions in Psychological Science, 14, 102-105. https://psycnet.apa.org/doi/10.1111/j.0963-7214.2005.00343.x

Cohen, E. B. (2009). A philosophy of informing science. Informing Science: The International Journal of an Emerging Transdiscipline, 12, 1-15. Retrieved from http://www.inform.nu/Articles/Vol12/ISJv12p001-015Cohen399.pdf

Constant, D., Kiesler, S., \& Sproull, L. (1994). What's mine is ours, or is it? A study of attitudes about information sharing. Information Systems Research, 5, 400-421. https://doi.org/10.1287/isre.5.4.400

Copeland, W. E., Wolke, D., Lereya, S. T., Shanahan, L., Worthman, C., \& Costello, E. J. (2014). Childhood bullying involvement predicts low-grade systemic inflammation into adulthood. Proceedings of the National Academy of Sciences, 111(21), 7570-7575. https:// doi.org/10.1073/pnas.1323641111

Davetian, B. (2009). Civility: A cultural history. Toronto, ON: University of Toronto Press.

Dawkins, R. (1976). The selfish gene. Oxford, UK: Oxford University Press.

de Freitas, L., Morin, E., \& Nicolescu, B. (1994). Charter of transdisciplinarity (K.-C. Voss, Trans.). Retrieved from http://cirettransdisciplinarity.org/chart.php\#en

Della Chiesa, B., Christoph, V., \& Hinton, C. (2009). How many brains does it take to build a new light: Knowledge management challenges of a transdisciplinary project. Mind, Brain, and Education, 3, 17-26. https://doi.org/10.1111/j.1751-228X.2008.01049.x

de Vries, A., de Vries, R. E., \& Born, M. P. (2011). Broad versus narrow traits: Conscientiousness and honesty-humility as predictors of academic criteria. European Journal of Personality, 25, 336-348. https://doi.org/10.1002/per.795

Dijkstra, J. K., \& Gest, S. D. (2015). Peer norm salience for academic achievement, prosocial behavior, and bullying: Implications for adolescent school experiences. The Journal of Early Adolescence, 35, 79-96. https://doi.org/10.1177/0272431614524303

Dixon, M. J., Smilek, D., Cudahy, C., \& Merikle, P. M. (2000). Five plus two equals yellow. Nature, 406, 365.

Dunbar, R. I. (2009). The social brain hypothesis and its implications for social evolution. Annals of Human Biology, 36, 562-572. https:// doi.org/10.1080/03014460902960289

Du Plessis, H., Sehume, J., \& Martin, L. (2014). The concept and application of transdisciplinarity in intellectual discourse and research. Johannesburg, South Africa: Mapungubwe Institute for Strategic Reflection (MISTRA) and Real African Publishers.

Ellis, B., Volk, A., Gonzalez, J-M., \& Embry, D. (2016). The meaningful roles intervention: An evolutionary approach to reducing bullying and increasing prosocial behavior. Journal of Research on Adolescence, 26, 622-637. https://doi.org/10.1111/jora.12243

Feldmann, L. J. (2001). Classroom civility is another of our instructor responsibilities. College Teaching, 49, 137-140. https://doi.org/10. $1080 / 87567555.2001 .10844595$

Freeman, M. (Ed.). (2018). Children's rights: New issues, new themes, new perspectives. Boston, MA: Brill Nijhoff.

Gaffney, H., Ttofi, M. M., \& Farrington, D. P. (2018). Evaluating the effectiveness of school-bullying prevention programs: An updated meta-analytical review. Aggression and Violent Behavior, 1(1), 14-31. https://doi.org/10.1007/s42380-019-0007-4

Garandeau, C. F., Lee, I. A., \& Salmivalli, C. (2014). Differential effects of the KiVa anti-bullying program on popular and unpopular bullies. Journal of Applied Developmental Psychology, 35, 44-50. https://psycnet.apa.org/doi/10.1016/j.appdev.2013.10.004

Gillis, D., Nelson, J., Driscoll, B., Hodgins, K., Fraser, E., \& Jacobs, S. (2017). Interdisciplinary and transdisciplinary research and education in Canada: A review and suggested framework. CELT-Collected Essays on Learning and Teaching, 10, 203-223. https://doi. org/10.22329/celt.v10i0.4745

Gloppen, K., McMorris, B., Gower, A., \& Eisenberg, M. (2018). Associations between bullying involvement, protective factors, and mental 
health among American Indian youth. American Journal of Orthopsychiatry, 88, 413-421. https://psycnet.apa.org/doi/10.1037/ ort0000284

Goodboy, A. K., Martin, M. M., \& Rittenour, C. E. (2016). Bullying as a display of social dominance orientation. Communication Research Reports, 33, 159-165. https://doi.org/10.1080/08824096.2016.1154838

Groen, T. P., Vasbinder, J. W., Andersson, B., Arthur, W. B., Boasson, M., Boer, de, R., ... \& Willems, R. (2010). Transdisciplinary EU science institute needs funds urgently. Nature, 463, 876. https://doi.org/10.1038/463876a

Haines-Saah, R. J., Hilario, C. T., Jenkins, E. K., Ng, C. K., \& Johnson, J. L. (2018). Understanding adolescent narratives about "bullying" through an intersectional lens: Implications for youth mental health interventions. Youth \& Society, 50, 636-658. https://doi. org/10.1177\%2F0044118X15621465

Hammarberg, T. (1990). The UN convention on the rights of the child-and how to make it work. Human Rights Quarterly, 12, 97-105. https://doi.org/10.2307/762167

Han, S. H., Brazeal, L. M., \& Pennington, N. (2018). Is civility contagious? Examining the impact of modeling in online political discussions. Social Media + Society, 4, 1-12. https://doi.org/10.1177\%2F2056305118793404

Hanawalt, B. A. (1995). Growing up in medieval London: the experience of childhood in history. Oxford, UK: Oxford University Press.

Hefner, R. (2018). Democratic civility: The history and cross cultural possibility of a modern political ideal. New York, NY: Routledge.

Hepworth, D. H., Rooney, R. H., Rooney, G. D., \& Strom-Gottfried, K. (2017). Direct social work practice: Theory and skills (10th ed.). Boston, MA: Nelson Education.

Higonnet, M. R. (1992). Civility books, child citizens, and uncivil antics. Poetics Today, 13(1), 123-140. https://www.jstor.org/ stable/1772793

Holben, D. M., \& Zirkel, P. A. (2014). School bullying litigation: An empirical analysis of the case law. Akron Law Review, 47, 299-328. Retrieved from https://ideaexchange.uakron.edu/cgi/viewcontent.cgi?referer=https://www.google. $\mathrm{ca} /$ \&httpsredir=1\&article $=1014 \&$ context=akronlawreview

Holt, M. K., Green, J. G., Tsay-Vogel, M., Davidson, J., \& Brown, C. (2017). Multidisciplinary approaches to research on bullying in adolescence. Adolescent Research Review, 2, 1-10. https://doi.org/10.1007/s40894-016-0041-0

Hong, J. S., Espelage, D. L., Hunter, S. C., \& Allen-Meares, P. (2018). Integrating multi-disciplinary social science theories and perspectives to understand school bullying and victimization. In J. L. Ireland, P. Birch, \& C. A. Ireland (Eds.), International handbook of human aggression (pp. 1-37). New York, NY: Routledge.

Hong, J. S., Peguero, A. A., \& Espelage, D. L. (2018). Experiences in bullying and/or peer victimization of vulnerable, marginalized, and oppressed children and adolescents: An introduction to the special issue. American Journal of Orthopsychiatry, 88, 399-401. https://psycnet.apa.org/doi/10.1037/ort0000330

Hyun, E. (2011). Transdisciplinary higher education curriculum: A complicated cultural artifact. Research in Higher Education Journal, 11, 1-19. Retrieved from https://www.aabri.com/manuscripts/11753.pdf

Jacobs, I. M., \& Nienaber, S. (2011). Waters without borders: Transboundary water governance and the role of the "transdisciplinary individual" in Southern Africa. Water SA, 37, 665-678. http://dx.doi.org/10.4314/wsa.v37i5.4

Juvonen, J., \& Graham, S. (2014). Bullying in schools: The power of bullies and the plight of victims. Annual Review of Psychology, 65, 159-185. https://doi.org/10.1146/annurev-psych-010213-115030

Kauffman, J. M., \& Burbach, H. J. (1998). Creating classroom civility. The Education Digest, 63, 12-18.

Kelly, K. R. (2017). Identifying and coping with academic incivility, Part I: The academic department. The Department Chair, 28, 20-22. https://doi.org/10.1002/dch.30155

Kueffer, C., Underwood, E., Hirsch Hadorn, G., Holderegger, R., Lehning, M., Pohl, C., \& Edwards P. (2012). Synthesis: Enabling effective 
problem-oriented research for sustainable development. Ecology and Society, 17(4), 8. http://dx.doi.org/10.5751/ES-05045170408

Leavy, P. (2011). Essentials of transdisciplinary research: Using problem-centered methodologies. Walnut Creek, CA: Left Coast Press.

Levesque, R. J. (2000). Adolescents, sex, and the law: Preparing adolescents for responsible citizenship. Washington, DC: American Psychological Association.

Lim, F. A., \& Bernstein, I. (2014). Civility and workplace bullying: Resonance of Nightingale’s persona and current best practices. Nursing Forum, 49, 124-129. https://doi.org/10.1111/nuf.12068

Make Children Better Now Association. (2019). Website. Retrieved from http://makechildrenbetternow.com/

Manderson, D. (2000). Some considerations about transdisciplinarity: A new metaphysics? In M. A. Somerville \& D. J. Rapport (Eds), Transdisciplinarity: Recreating integrated knowledge (pp. 86-93). Montreal, QC: McGill-Queen’s Press.

Margoni, F., Baillargeon, R., \& Surian, L. (2018). Infants distinguish between leaders and bullies. Proceedings of the National Academy of Science, 1-9. https://doi.org/10.1073/pnas.1801677115

Marini, Z. A. (2007). Understanding and fostering civility in university classrooms: Seminar leaders as agents of civic engagement [Research proposal, Brock Chancellor's Chairs for Teaching Excellence]. Unpublished manuscript, Brock University.

Marini, Z. (2009). The thin line between civility and incivility: Fostering reflection and self-awareness to create a civil learning community. Collected Essays on Learning and Teaching, 2, 61-67. https://doi.org/10.22329/celt.v2i0.3204

Marini, Z., Polihronis, C., \& Blackwell, W. (2010). Academic in/civility: Co-constructing the foundation for a civil learning community. Collected Essays on Learning and Teaching, 3, 89-93. https://doi.org/10.22329/celt.v3i0.3245

Marini, Z. A., \& Volk, A. A. (2017). Towards a transdisciplinary blueprint to studying bullying. Journal of Youth Studies, 20, 94-109. https://doi.org/10.1080/13676261.2016.1184239

Martin, V. (2017). Transdisciplinarity revealed: What librarians need to know. Santa Barbara, CA: Libraries Unlimited.

Martinez, S. (2009). A system gone berserk: How are zero-tolerance policies really affecting schools? Preventing School Failure: Alternative Education for Children and Youth, 53(3), 153-158. https://doi.org/10.3200/PSFL.53.3.153-158

Mazzone, A., Thornberg, R., Stefanelli, S., Cadei, L., \& Caravita, S. C. (2018). "Judging by the cover": A grounded theory study of bullying towards same-country and immigrant peers. Children and Youth Services Review, 91, 403-412. http://dx.doi.org/10.1016\%2Fj. childyouth.2018.06.029

McLuhan, M. (1964). The medium is the message. Chapter 1 in Understanding media: The extension of man (pp. 1-18). Retrieved from https://web.mit.edu/allanmc/www/mcluhan.mediummessage.pdf

Melander, L. A., Hartshorn, K. J. S., \& Whitbeck, L. B. (2013). Correlates of bullying behaviors among a sample of North American Indigenous adolescents. Journal of adolescence, 36, 675-684. https://dx.doi.org/10.1016\%2Fj.adolescence.2013.05.003

Mitchell, R. C., \& Moore, S. A. (Eds.). (2015a). Planetary praxis and pedagogy: Transdisciplinary approaches to environmental sustainability. Rotterdam, Boston, and Taipei: Sense.

Mitchell, R. C., \& Moore, S. A. (2015b). Muse, ruse, and subterfuge: Transdisciplinary praxis in Ontario's PSE bricolage?” Review of Education, Pedagogy, and Cultural Studies, 35(5), 393-413. https://doi.org/10.1080/10714413.2015.1091257

Mitchell, R. C., \& Moore, S. A. (2018). Introduction to 2-volume special issue: Transdisciplinary child and youth studies: Critical praxis, global perspectives. World Futures: The Journal of New Paradigm Research, 74(7-8), 450-470. https://doi.org/10.1080/026040 27.2018 .1485435

Montuori, A. (2008). Foreword. In B. Nicolescu (Ed.), Transdisciplinarity: Theory and practice (pp. ix-xvii). Cresskill, NJ: Hampton Press.

Montuori, A. (2010). Transdisciplinarity and creative inquiry in transformative education: Researching the research degree. In M. 
Maldonato \& R. Pietrobon (Eds.), Research on scientific research: A transdisciplinary study (pp. 110-135). Brighton, UK: Sussex Academic Press.

Montuori, A. (2013). Complexity and transdisciplinarity: Reflections on theory and practice. World Futures: The Journal of Global Education, 69, 200-230. https://doi.org/10.1080/02604027.2013.803349

Morin, E. (1999). Seven complex lessons in education for the future. Paris, France: UNESCO.

Morin, E., \& Kern, B. (1999). Homeland earth: A manifesto for the new millennium. Cresskill, NJ: Hampton Press.

Nicolescu, B. (2002). Manifesto of transdisciplinarity. New York, NY: SUNY Press.

Nicolescu, B. (Ed.). (2008). Transdisciplinarity: Theory and practice. Cresskill, NJ: Hampton Press.

Nwanevu, O. (2018). John McCain and the limits of civility. New Yorker. Retrieved from https://www.newyorker.com/news/news-desk/ john-mccain-and-the-limits-of-civility

Olthof, T., Goossens, F. A., Vermande, M. M., Aleva, E. A., \& van der Meulen, M. (2011). Bullying as strategic behavior: Relations with desired and acquired dominance in the peer group. Journal of School Psychology, 49, 339-359. https://doi.org/10.1016/j. jsp.2011.03.003

Papacharissi, Z. (2004). Democracy online: Civility, politeness, and the democratic potential of online political discussion groups. New Media \& Society, 6, 259-283. https://doi.org/10.1177\%2F1461444804041444

Pellegrini, A. D., \& Long, J. D. (2002). A longitudinal study of bullying, dominance, and victimization during the transition from primary school through secondary school. British Journal of Developmental Psychology, 20, 259-280. https://doi. org/10.1348/026151002166442

Pepler, D., Cummings, J., \& Craig, W. (Eds). (2016). Healthy development, healthy communities. Ottawa, ON: Gilmore Printing.

Pepler, D., Waddell, J., Jiang, D., Craig, W., Connolly, J., \& Lamb, J. (2006). Aggressive girls' health and parent-daughter conflict. Retrieved from https://tspace.library.utoronto.ca/bitstream/1807/9492/1/pepler_etal.pdf

Pinker, S. (2018). Enlightenment now: The case for reason, science, humanism, and progress. Toronto, ON: Penguin Books.

Plimmer, G., Proctor-Thomson, S., Donnelly, N., \& Sim, D. (2017). The mistreatment of public service workers: Identifying key risk and protective factors. Public Money \& Management, 37, 333-340. https://doi.org/10.1080/09540962.2017.1328186

Pohl, C. (2005). Transdisciplinary collaboration in environmental research. Futures, 37, 1159-1178. http://dx.doi.org/10.1016/j. futures.2005.02.009

Pohl, C., \& Hirsch Hadorn, G. (2007). Principles for designing transdisciplinary research. Munich, Germany: Oekom Verlag.

Pohl, C., \& Hirsch Hadorn, G. (2008). Methodological challenges of transdisciplinary research. Natures Sciences Sociétés, 16, 111-121. Retrieved from https://www.cairn.info/revue-natures-sciences-societes-2008-2-page-111.htm?try_download=1\#

Pouratashi, M., \& Zamani, A. (2017). How faculty members' personality traits influence their education research performance. New Educational Review, 50, 70-82. https://doi.org/10.15804/tner.2017.50.4.06

Pronk, J., Lee, N. C., Sandhu, D., Kaur, K., Kaur, S., Olthof, T., \& Goossens, F. A. (2017). Associations between Dutch and Indian adolescents' bullying role behavior and peer-group status: Cross-culturally testing an evolutionary hypothesis. International Journal of Behavioral Development, 41, 735-742. https://psycnet.apa.org/doi/10.1177/0165025416679743

Puhl, R. M., Latner, J. D., O’Brien, K., Luedicke, J., Forhan, M., \& Danielsdottir, S. (2016). Cross-national perspectives about weight-based bullying in youth: nature, extent and remedies. Pediatric Obesity, 11, 241-250. https://doi.org/10.1111/ijpo.12051

Pye, L. W. (1999). Civility, social capital, and civil society: Three powerful concepts for explaining Asia. Journal of Interdisciplinary History, 29, 763-782. Retrieved from https://numerons.files.wordpress.com/2012/04/civility-social-capital-and-civil-society-explaining-asiamit-paper.pdf 
Reijntjes, A., Vermande, M., Goossens, F. A., Olthof, T., van de Schoot, R., Aleva, L., \& van der Meulen, M. (2013). Developmental trajectories of bullying and social dominance in youth. Child Abuse \& Neglect, 37, 224-234. https://psycnet.apa.org/doi/10.1016/j. chiabu.2012.12.004

Rinderu, M. I., Bushman, B. J., \& Van Lange, P. A. (2018). Climate, aggression, and violence (CLASH): A cultural-evolutionary approach. Current Opinion in Psychology, 19, 113-118. https://doi.org/10.1016/j.copsyc.2017.04.010

Roland, E. (2011). The broken curve: Effects of the Norwegian manifesto against bullying. International Journal of Behavioral Development, 35, 383-388. https://doi.org/10.1177\%2F0165025411407454

Rossi, G., Lenzi, M., Sharkey, J. D., Vieno, A., \& Santinello, M. (2016). Factors associated with civic engagement in adolescence: The effects of neighborhood, school, family, and peer contexts. Journal of Community Psychology, 44, 1040-1058. https://doi.org/10.1002/ jcop.21826

Safaria, T., \& Yunita, A. (2014). The efficacy of art therapy to reduce anxiety among bullying victims. International Journal of Research Studies in Psychology, 3, 77-88. https://doi.org/10.1371/journal.pone.0208716

Sentse, M., Veenstra, R., Kiuru, N., \& Salmivalli, C. (2015). A longitudinal multilevel study of individual characteristics and classroom norms in explaining bullying behaviors. Journal of Abnormal Child Psychology, 43, 943-955. https://psycnet.apa.org/doi/10.1007/ s10802-014-9949-7

Shapin, S. (1994). A social history of truth: Civility and science in seventeenth-century England. Chicago, IL: The University of Chicago Press.

Sijtsema, J. J., Veenstra, R., Lindenberg, S., \& Salmivalli, C. (2009). Empirical test of bullies's status goals: Assessing direct goals, aggression, and prestige. Aggressive Behavior, 35, 57-67. https://doi.org/10.1002/ab.20282

Slotow, R., van Dyk, G., Poole, J., Page, B., \& Klocke, A. (2000). Older bull elephants control young males. Nature, 408(6811), 425-426. https://doi.org/10.1038/35044191

Smith, P. K., Kwak, K., \& Toda, Y. (Eds.). (2016). School bullying in different cultures. Cambridge, UK: Cambridge University Press.

Smith, P. K., Salmivalli, C., \& Cowie, H. (2012). Effectiveness of school-based programs to reduce bullying: A commentary. Journal of Experimental Criminology, 8, 433-441. https://psycnet.apa.org/doi/10.1007/s11292-012-9142-3

Somerville, M. A., \& Rapport, D. J. (2000). Transdisciplinarity: Recreating integrated knowledge. Oxford, UK: EOLSS Publishers.

Spadafora, N., Farrell, A. H., Provenzano, D. A., Marini, Z. A., \& Volk, A. A. (2018). Temperamental differences and classroom incivility: Exploring the role of individual differences. Canadian Journal of School Psychology, 33, 44-62. https://doi. org/10.11772F0829573516648946

Spadafora, N., Marini, Z. A., \& Volk, A. A. (2018). Should I defend or should I go?: An adaptive, qualitative examination of the personal costs and benefits associated with bullying intervention. Canadian Journal of School Psychology, 1-18. https://doi. org/10.11772F0829573518793752

Spadafora, N., Volk, A. A., Molnar, D., \& Frijters, J. (submitted). Personality and civility. Journal of Social School Psychology.

Spiel, C., Salmivalli, C., \& Smith, P. K. (2011). Translational research: National strategies for violence prevention in school. International Journal of Behavioral Development, 35(5), 381. https://doi.org/10.1177\%2F0165025411407556

Steinberg, L. (2008). A social neuroscience perspective on adolescent risk-taking. Developmental Review, 28, 78-106. https://dx.doi. org/10.1016\%2Fj.dr.2007.08.002

Thiranagama, S., Kelly, T., \& Forment, C. (2018). Introduction: Whose civility? Anthropological Theory, 18, 153-174. https://doi. org/10.11772F1463499618780870

Thomas, H. J., Connor, J. P., \& Scott, J. G. (2018). Why do children and adolescents bully their peers? A critical review of key theoretical frameworks. Social Psychiatry and Psychiatric Epidemiology, 53, 437-451. https://doi.org/10.1007/s00127-017-1462-1 
Thornberg, R. (2015). Distressed bullies, social positioning and odd victims: Young people's explanations of bullying. Children \& Society, 29, 15-25. https://doi.org/10.1111/chso.12015

Towns, A. E. (2010). Women and states: Norms and hierarchies in international society. Cambridge, MA: Cambridge University Press.

Ttofi, M. M., \& Farrington, D. P. (2011). Effectiveness of school-based programs to reduce bullying: A systematic and meta-analytic review. Journal of Experimental Criminology, 7, 27-56. Retrieved from http://njbullying.org/documents/ttofifarrington2011.pdf

Vaillancourt, T., McDougall, P., Hymel, S., Krygsman, A., Miller, J., Stiver, K., \& Davis, C. (2008). Bullying: Are researchers and children/ youth talking about the same thing? International Journal of Behavioral Development, 32, 486-495. https://psycnet.apa.org/ doi/10.1177/0165025408095553

Volk, A. A. (2011). The history of childhood. Journal of the History of Childhood and Youth, 4, 470-493. https://doi.org/10.1353/ hcy. 2011.0042

Volk, A. A., Camilleri, J., Dane, A., \& Marini, Z. (2012). Is adolescent bullying an evolutionary adaptation? Aggressive Behavior, 38, 222-238. https://doi.org/10.1002/ab.21418

Volk, A. A., Dane, A., V., \& Marini, Z. A. (2014). What is bullying? A theoretical redefinition. Developmental Review, 34, $327-343$. Retrieved from https://daneshyari.com/article/preview/353475.pdf

Volk, A. A., Marini, Z. A., \& Dane, A. V. (2016). The relations between incivility and adolescent health and wellbeing. Advances in Social Sciences Research Journal, 3, 79-86. https://doi.org/10.14738/assrj.39.2224

Volk, A. A., Provenzano, D. A., Farrell, A. H., Dane, A. V., \& Shulman, E. P. (2019). Personality and bullying: Pathways to adolescent social dominance. Current Psychology, Advance online publication. https://psycnet.apa.org/doi/10.1007/s12144-019-00182-4

Volk, A. A., Schiralli, K., Xia, X., Zhao, J., \& Dane, A. V. (2018). Adolescent bullying and personality: A cross-cultural approach. Personality and Individual Differences, 125, 126-132. https://doi.org/10.1016/j.paid.2018.01.012

Volk, A. A., Veenstra, R., \& Espelage, D. L. (2017). So you want to study bullying? Recommendations for enhancing the validity, transparency, and compatibility of bullying research. Aggression and Violent Behavior, 36, 34-43. https://doi.org/10.1016/j. avb.2017.07.003

Walton, G., \& Niblett, B. (2013). Investigating the problem of bullying through photo elicitation. Journal of Youth Studies, 16, 646-662. https://doi.org/10.1080/13676261.2012.733810

Wedekind, C., \& Braithwaite, V. A. (2002). The long-term benefits of human generosity in indirect reciprocity. Current Biology, 12, 1012-1015. https://psycnet.apa.org/doi/10.1016/S0960-9822(02)00890-4

Wilkins, K., Caldarella, P., Crook-Lyon, R., \& Young, K. R. (2010). Implications of civility for children and adolescents: A review of the literature. Issues in Religion and Psychotherapy, 33, 37-45. Retrieved from https://pdfs.semanticscholar.org/58f1/f649a1705daf 2e1f4d30dd7c7e92b34f7ffd.pdf

Wohlleben, P. (2016). The hidden life of trees: What they feel, how they communicate: Discoveries from a secret world. Vancouver, BC: Greystone Books.

Ybarra, M. L., Espelage, D. L., \& Mitchell, K. J. (2014). Differentiating youth who are bullied from other victims of peer-aggression: The importance of differential power and repetition. Journal of Adolescent Health, 55(2), 293-300. https://dx.doi.org/10.1016\%2Fj. jadohealth.2014.02.009

Yeager, D. S., Fong, C. J., Lee, H. Y., \& Espelage, D. L. (2015). Declines in efficacy of anti-bullying programs among older adolescents: Theory and a three-level meta-analysis. Journal of Applied Developmental Psychology, 37, 36-51. https://doi.org/10.1016/j. appdev.2014.11.005

Young, J. R. (2018). Twitter is funding research into online civility. Here's how one project will work. EdSurge. Retrieved from https:// www.edsurge.com/news/2018-08-14-twitter-is-funding-research-into-online-civility-here-s-how-one-project-will-work

Youniss, J., \& Yates, M. (1999). Youth service and moral-civic identity: A case for everyday morality. Educational Psychology Review, 11, 
361-376. https://psycnet.apa.org/doi/10.1023/A:1022009400250

Zych, I., Ortega-Ruiz, R., \& Del Rey, R. (2015). Systematic review of theoretical studies on bullying and cyberbullying: Facts, knowledge, prevention, and intervention. Aggression and Violent Behavior, 23, 1-21. https://doi.org/10.1016/j.avb.2015.10.001

\section{(Endnotes)}

$1 \quad$ The evidence very strongly suggests that individuals who are both bullies and victims do not obtain the same benefits as those who are only bullies and experience far more negative costs associated with bullying (Volk et al., 2014). The focus of this paper is on "pure" bullies, who commit the majority of bullying episodes. 